\title{
Balance studies in patients with intestinal resection: how long is enough?
}

\author{
BY HANS TORNQVIST*, AILA RISSANEN \\ AND HENRIK ANDERSSON \\ Department of Clinical Nutrition, Sahlgren's Hospital, Gothenburg, Sweden
}

(Received 19 September 1985 - Accepted 14 January 1986)

\begin{abstract}
1. Results from two independent metabolic balance studies in patients with ileal resection with or without a remaining colon were examined to assess the precision of the mineral, protein and fat balances obtained.

2. Low day-to-day variation in balances was found in patients with ileostomy/jejunostomy, irrespective of formula diet composition. In contrast, patients with a remaining colon showed considerable variation, with reliable cumulative balances often not reached for many weeks.

3. In conclusion, short-term cumulative balances can be performed with good precision in patients with ileostomy or jejunostomy.
\end{abstract}

Metabolic balance studies of healthy volunteers and patients without gastrointestinal diseases have been conducted for many years (Reifenstein et al. 1945). The method is time-consuming and laborious. To reflect adequately the balance between intake and faecal, urinary and other losses, it requires special facilities, adaptation to a 'constant diet', exact estimation of intake corrected by determination of returns and a meticulous quantitative collection of urine and stools (Isaksson et al. 1965). Despite these precautions against systematic errors, it is still uncertain whether reliable values of cumulative balance are reached even after 1 month of continuous collections. This can clearly be seen for nutrients that are, to a minor part, absorbed from the gut, such as calcium (Malm, 1958; Isaksson \& Sjögren, 1967a). The imprecision is suggested to be largely due to delay of faecal output. It seems reasonable, therefore, to assume that less time-consuming balance studies could be performed in patients with well-established intestinal resection, especially when colectomy has been performed.

The aim of the present study was to evaluate and compare the reliability of balance studies in patients with ileopathy and a functioning colon, and in patients subjected to colectomy with minor and more extensive resection of the small intestine. It is concluded that nutritional balance in colectomized patients can be reliably estimated after an adequate balance study of some consecutive 24 -h periods on a constant diet.

\section{EXPERIMENT A L}

Values from two different balance studies (Andersson et al. 1974, 1984) were used to calculate the variance of cumulative balances of $\mathrm{Ca}$, magnesium, sodium, potassium, nitrogen and lipids. In the first study (Andersson et al. 1974), balances were performed for six to seven 4-d periods on a constant low-fat diet ( $40 \mathrm{~g}$ fat $/ \mathrm{d})$ in nine patients with Crohn's disease of the ileum and two patients previously subjected to a limited small-bowel resection for other reasons, all with their colon intact. Values from two patients (M191 and M216) in the initial study were excluded due to colectomy and the initial values were not available.

\footnotetext{
* Present address: Diabetes Unit, Massachusetts General Hospital, Wellman 340, Boston, Massachusetts 02114, USA.
} 
Table 1. Within-patient-within-diet variation (s) in cumulative balances (mmol/24 h) in two groups of patients: $(A)$ jejunostomy/ileostomy after colectomy and short-bowel resection and $(B)$ patients with ileal disease or ileocaecal resection with remaining colon

(These values were recalculated to standard errors of the mean of four consecutive days $\left(\mathrm{SE}_{4}\right)$ or fifty-six consecutive days $\left(\mathrm{SE}_{56}\right)$ for comparisons between the groups; ranges for balances obtained in each group are also given)

(A) Colectomy and short-bowel resection

\begin{tabular}{|c|c|c|c|c|c|c|c|c|c|c|c|c|}
\hline & \multicolumn{4}{|c|}{$<1 \mathrm{~m}$ resected } & \multicolumn{4}{|c|}{$>1 \mathrm{~m}$ resected } & \multicolumn{4}{|c|}{$\begin{array}{l}\text { (B) Ileal disease/ileocaecal } \\
\text { resection and remaining colon }\end{array}$} \\
\hline & $s$ & $n$ & $\mathrm{SE}_{4}$ & Range* & $s$ & $n$ & $\mathrm{SE}_{4}$ & Range* & $s$ & $n$ & $\mathrm{SE}_{56}$ & Range $\dagger$ \\
\hline Calcium & $3 \cdot 0$ & 54 & $1 \cdot 5$ & $-8 \cdot 3-16 \cdot 3$ & $2 \cdot 8$ & 98 & $1 \cdot 4$ & $-19 \cdot 0-16 \cdot 3$ & $5-6$ & 51 & 1.5 & $-22.8-18.0$ \\
\hline Magnesium & $3 \cdot 7$ & 58 & 1.9 & $-20 \cdot 4-7 \cdot 3$ & 1.8 & 76 & 0.9 & $-14 \cdot 7-7 \cdot 2$ & - & - & - & - \\
\hline Nitrogen & $2 \cdot 0$ & 58 & 1.0 & $-7 \cdot 2-7 \cdot 4$ & $2 \cdot 1$ & 101 & $1 \cdot 1$ & $-14 \cdot 8-9 \cdot 6$ & $7 \cdot 1$ & 57 & 1.9 & $-4 \cdot 0-61 \cdot 2$ \\
\hline Sodium & 30.9 & 58 & $15 \cdot 4$ & $-118-152$ & $54 \cdot 1$ & 97 & $27 \cdot 1$ & $-162-239$ & $70 \cdot 8$ & 58 & $18 \cdot 9$ & $-176-225$ \\
\hline Potassium & $13 \cdot 0$ & 58 & $6 \cdot 5$ & $-43-57$ & 19.6 & 98 & 9.8 & $-70-58$ & $55 \cdot 2$ & 58 & 14.8 & $-189-134$ \\
\hline Lipids & 0.8 & 56 & 0.4 & $0 \cdot 3-7 \cdot 2$ & $3 \cdot 9$ & 102 & 1.9 & $0.6-64.9$ & $4 \cdot 0$ & 58 & $1 \cdot 1$ & $1 \cdot 2-35 \cdot 6$ \\
\hline
\end{tabular}

* 24-h balances. † 4-d balances.

The second study (Andersson et al. 1984) comprised sixteen well-established ileostomy patients given three different constant-formula diets by means of a pumped infusion through a nasogastric tube for $4-5 \mathrm{~d}$. Values from an additional patient treated likewise have been added to the initial study. All had an ileostomy and their colon removed due to ulcerative colitis or Crohn's disease. Seven patients had been subjected to no or limited ileal resection $(<1 \mathrm{~m})$ and ten to a more extensive ileal resection. The different enteral diets given were a moderate-fat polymeric diet (Nutrauxil ${ }^{\circledR}$, KabiVitrum, Sweden), a low-fat, powder-based peptide elemental diet (Nutrauxil PD ${ }^{\circledR}$, KabiVitrum), a low-fat polymeric diet (KabiVitrum). A constant amount of each diet was given for 4-5 d, and balances were calculated after an initial adaptation day. Extra supplementation with $\mathrm{Na}$ and $\mathrm{K}$ was given according to needs. Both studies had been approved by the local ethical committee.

Analysis of $\mathrm{Ca}, \mathrm{Mg}, \mathrm{Na}, \mathrm{K}, \mathrm{N}$ and lipids in samples of urine and freeze-dried foods, ileostomy contents and stools were performed as described by Andersson et al. $(1974,1984)$. Total balance was calculated as the dietary intake minus urinary excretion and losses in stools or ileostomy contents. No corrections were made for dermal losses.

One-way analysis of variance was performed to evaluate residual variance as a measure of precision (Snedecor \& Cochran, 1980).

\section{RESULTS}

Day-to-day variations of balances for $\mathrm{Ca}, \mathrm{Mg}, \mathrm{Na}, \mathrm{K}, \mathrm{N}$ and lipids were calculated for the different groups of patients (Table 1): (group A) ileostomists with no or limited short-bowel resection $(<1 \mathrm{~m})$ or more extensive resection $(>1 \mathrm{~m}$ ), (group B) those with ileal disease or ileocaecal resection with a remaining colon. Variations were considerably smaller in group A than in group B. To achieve the same precision in group B as in group A, a balance study of much longer duration would be needed. For instance, to reach a standard error of $1.5 \mathrm{mmol} / 24 \mathrm{~h}$ for $\mathrm{Ca}$, as in ileostomists with $<1 \mathrm{~m}$ resection (group A) in a $4 \mathrm{~d}$ study, a balance study of more than $56 \mathrm{~d}$ in group $\mathrm{B}$ would be needed. Furthermore, variations in $\mathrm{Na}, \mathrm{K}$ and lipid balances in group $\mathrm{A}$ were higher in ileostomists with a large resection of the small intestine than in those with no or limited resection. 
Table 2. Within-patient-between-diet variation (s) in cumulative balances (mmol/24 h) in jejunostomists/ileostomists after colectomy and short-bowel resection given three different constant-formula diets for four or five consecutive $24 \mathrm{~h}$ periods

(Diets were (a) a moderate-fat polymeric diet; (b) a low-fat, powder-based peptide elemental diet; (c) a low-fat polymeric diet. Values are expressed as $s$ of daily measurements and as standard errors of the mean for four consecutive days $\left(\mathrm{SE}_{4}\right)$ ).

\begin{tabular}{|c|c|c|c|c|}
\hline Balance & Diet & $s$ & $n$ & $\mathrm{SE}_{4}$ \\
\hline \multirow[t]{3}{*}{ Calcium } & $\mathrm{a}$ & $2 \cdot 46$ & 46 & $1 \cdot 2$ \\
\hline & $\mathbf{b}$ & $3 \cdot 21$ & 58 & 1.6 \\
\hline & $\mathrm{c}$ & $2 \cdot 86$ & 48 & $1 \cdot 4$ \\
\hline \multirow[t]{3}{*}{ Magnesium } & $a$ & $2 \cdot 96$ & 46 & 1.4 \\
\hline & $\mathbf{b}$ & $3 \cdot 26$ & 49 & 1.6 \\
\hline & $\mathrm{c}$ & 1.80 & 39 & 0.9 \\
\hline \multirow[t]{3}{*}{ Nitrogen } & $\mathrm{a}$ & 1.99 & 55 & $1 \cdot 0$ \\
\hline & b & $2 \cdot 00$ & 58 & $1 \cdot 0$ \\
\hline & c & $2 \cdot 20$ & 48 & $1 \cdot 1$ \\
\hline \multirow[t]{3}{*}{ Sodium } & $\mathrm{a}$ & 55.0 & 50 & 28 \\
\hline & b & $33 \cdot 6$ & 57 & 17 \\
\hline & $\mathrm{c}$ & $50 \cdot 2$ & 48 & 25 \\
\hline \multirow[t]{3}{*}{ Potassium } & $\mathbf{a}$ & $24 \cdot 5$ & 50 & 12 \\
\hline & $\mathbf{b}$ & $11 \cdot 0$ & 58 & 6 \\
\hline & $\mathbf{c}$ & $14 \cdot 7$ & 51 & 7 \\
\hline \multirow[t]{3}{*}{ Lipids (g/24h) } & $\mathrm{a}$ & $3 \cdot 73$ & 57 & 1.9 \\
\hline & $\mathrm{b}$ & $2 \cdot 82$ & 56 & $1 \cdot 4$ \\
\hline & $\mathfrak{c}$ & $2 \cdot 55$ & 51 & $1 \cdot 3$ \\
\hline
\end{tabular}

In the study performed on ileostomy patients (group A), three different diets were tested on each patient. Values for the whole group were recalculated to estimate withinpatient-between-diet variations in the cumulative balances (Table 2). No major difference in variation between the three diets was detected for any of the nutrients presented.

The successive cumulative balance from day-to-day for each patient was plotted to see if there was any constant trend causing a systematic error. For ileostomy patients (group A), such trends were generally not seen. This is illustrated for Ca (Fig. 1). On the other hand, clear initial trends, sometimes alternating, were generally seen with patients with a remaining functioning colon (group B) as illustrated in Fig. 2.

\section{DISCUSSION}

The present study shows that reliable results of small-bowel mineral, protein and fat absorption could be obtained within some days in ileostomy or jejunostomy patients, while conventional balance techniques would take several weeks in volunteers with a remaining colon. Short-term studies of well-established ileostomy patients could thus be used to determine small-bowel uptake of nutrients. If the purpose of the study is to investigate substances degraded by the colonic flora, e.g. bile salts, dietary fibre or non-absorbed starch, the ileostomy bags must be changed every $2 \mathrm{~h}$ and immediately deep-frozen (Sandberg et al. 1981).

The present balance studies of ileostomy and jejunostomy patients were performed using a formula diet which could even out the results (Lentner et al. 1975). However, the present findings are in accordance with our earlier experience with similar patients eating a normal diet. Ileal excretion of bran fibre varied very little from day-to-day (Sandberg et al. 1981), as did the excretion of citrus pectin (Sandberg et al. 1983), when these fibre products were 

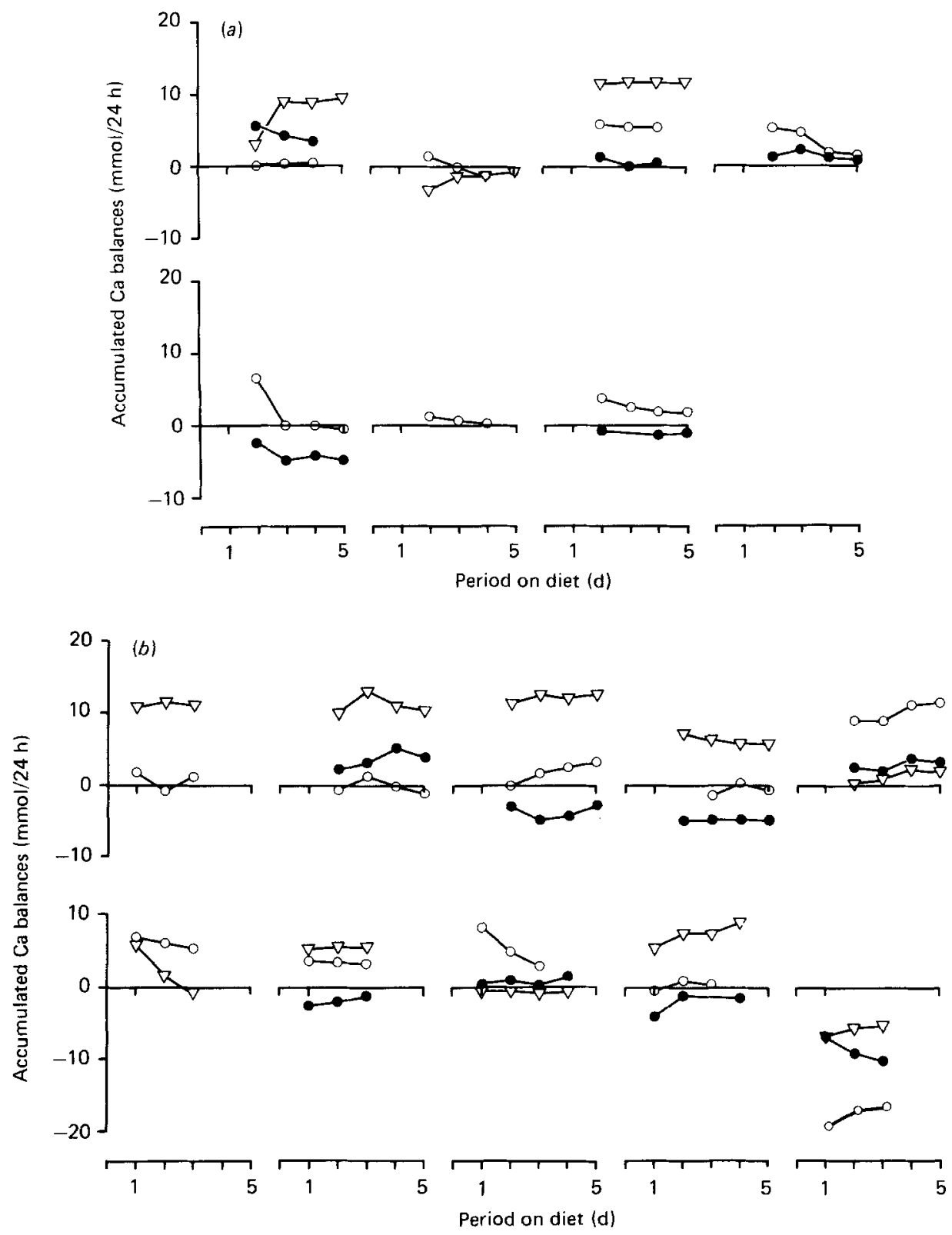

Fig. 1. Accumulated balances for calcium in single ileostomy patients with remaining short bowel $(a)$ $>1 \mathrm{~m}$ and $(b)<1 \mathrm{~m}$. They were all given the same constant-formula diets: $(O)$ a moderate fat diet, $(O)$ a low-fat, powder-based peptide elemental diet and $(\nabla)$ a low-fat polymeric diet.

added to a low-fibre diet. A minimal day-to-day variation in the excretion of $\mathrm{Ca}, \mathrm{Mg}$, zinc and iron (Sandberg et al. 1983) by ileostomy patients is in accordance with the present finding with $\mathrm{Ca}$ and $\mathrm{Mg}$ in similar patients.

The variation in output of ileostomy and jejunostomy patients is, of course, related to the amount excreted which means that the absolute variation of salt and fat excretion is 


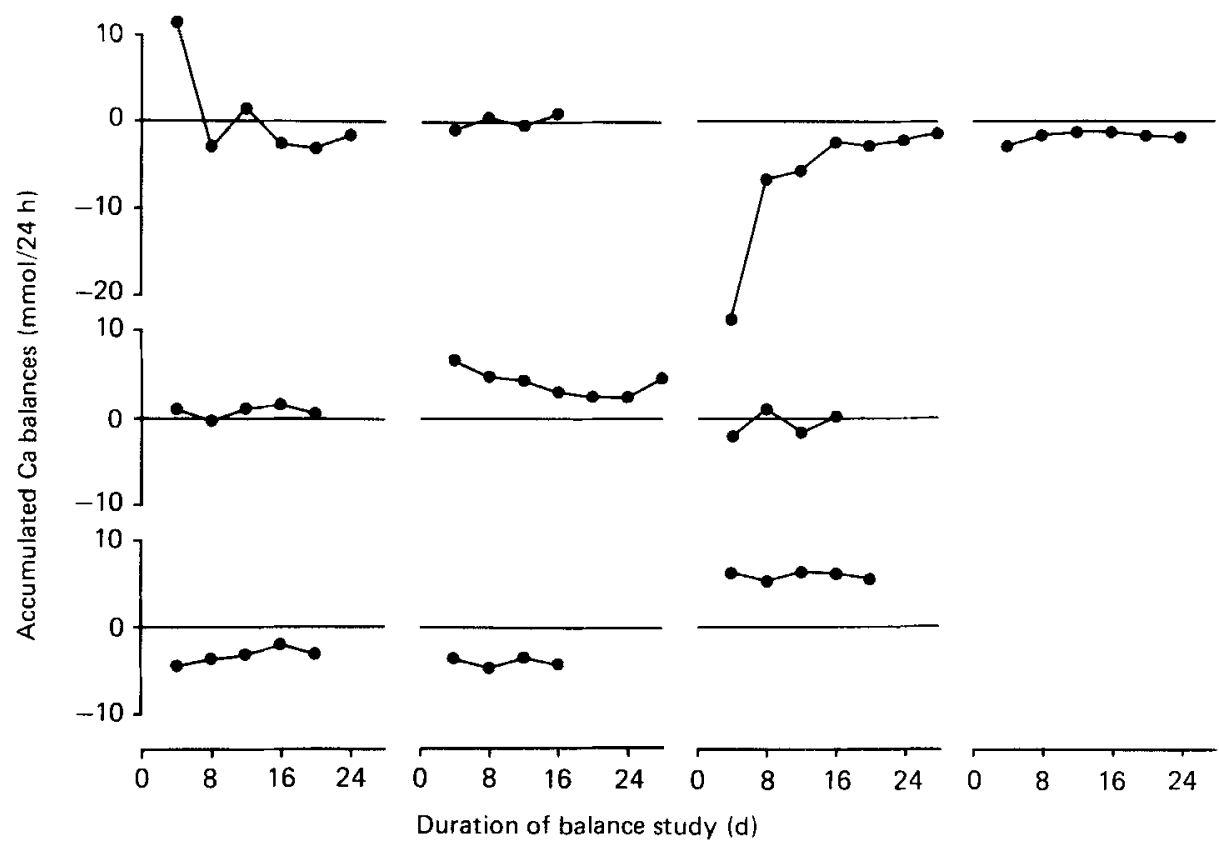

Fig. 2. Accumulated 4-d balances for calcium in single patients with ileal disease or ileocaecal resection and a remaining functioning colon. They were given a constant diet during the study. Note the difference in time scale when compared with Fig. 1.

greater in jejunostomy than in ileostomy patients. Taking this into account, it seems reasonable to assume that research work with short-term studies on small-bowel uptake and balance could be performed in ileostomy and jejunostomy patients but should be done preferably in ileostomists.

Some short-bowel patients, especially those with jejunostomy, may have deficiencies in specific nutrients or energy, or both. Short-term balance studies could be applied clinically to reveal their nutritional needs.

The present study also gives evidence that reliable results could not be achieved within some days in patients with ileal disease and a remaining colon. The role of the colon in these patients seems to be as important as that in healthy subjects (Isaksson \& Sjögren, $1967 b$ ) which means that the study should not be discontinued before the cumulative balance has attained a plateau for at least three or four 4-d periods. It is preferable, therefore, that isotope studies should be used in such patients.

\section{REFERENCES}

Andersson, H., Bosaeus, I., Ellegard, L., Hallgren, B., Hulten, L. \& Magnusson, O. (1984). Clinical Nutrition 3, $183-189$.

Andersson, H., Isaksson, B. \& Sjögren, B. (1974). Gut 15, 351-359.

Isaksson, B. \& Sjögren, B. (1967a). Proceedings of the Nutrition Society 26, 106-116.

Isaksson, B. \& Sjögren, B. (1967b). Metabolism 16, 295-302.

Isaksson, B., Sjögren, B. \& Weimers, G. (1965). Nutrieta et Dieta 7, 175-185.

Lentner, C., Lauffenburger, T., Guncaga, J., Dambacher, M. A. \& Haas, H. G. (1975). Metabolism 24, 461-471.

Malm, O. J. (1958). Scandinavian Journal of Clinical and Laboratory Investigation 10, Suppl.

Reifenstein, E. C. Jr, Albright, F. \& Wells, S. L. (1945). Journal of Clinical Endocrinology 5, 367-395. 
Sandberg, A.-S., Ahderinne, R., Andersson, H., Hallgren, B. \& Hulten, L. (1983). Human Nutrition: Clinical Nutrition 37 C, 171-183.

Sandberg, A.-S., Andersson, H., Hallgren, B., Hasselblad, K., Isaksson, B. \& Hulten, L. (1981). British Journal of Nutrition 45, 283-294.

Snedecor, G. W. \& Cochran, G. C. (1980). Statistical Methods, 7th ed, pp. 217-219. Ames, Iowa: Iowa State University Press. 